\title{
IMPORTÂNCIA DA COORDENAÇÃO NAS CADEIAS PRODUTIVAS: CASO DO PROGRAMA DE FRUTICULTURA DO OESTE GOIANO
}

Eloisa Helena Longhi ${ }^{l}$ Josemar Xavier de Medeiros ${ }^{2}$

Resumo: Este trabalho teve por objetivo analisar as dificuldades de coordenação no âmbito de uma cadeia produtiva frutícola no Estado de Goiás. O esforço na formulação e implementação de programas de fruticultura por parte do Estado, não levou na devida consideração o papel estruturante dos segmentos líderes na tarefa de coordenação, dificultando o efetivo desenvolvimento e inserção da atividade frutícola no contexto do Agronegócio. O estudo de caso do Programa de Fruticultura do Oeste Goiano é exemplar para analisar as variáveis que estão contribuindo para o insucesso dessas iniciativas. Para isso, a visão sistêmica do agronegócio serviu como fio condutor da análise, considerando a coordenação como elemento chave da competitividade.

Palavras-chaves: coordenação, visão sistêmica, cadeia produtiva frutícola.

\section{Introdução}

\section{Considerações Gerais}

O mercado mundial de frutas movimenta anualmente cerca de US $\$ 20$ bilhões e cresce cerca de US\$ 1 bilhão ao ano. Dependendo de como será conduzida, a cadeia produtiva frutícola brasileira será

Engenheíra Agrônoma, mestre em ciências agrárias, pesquisadora da AGENCIARURAL. E-mail: e.h.longhi@uol.com.br

2 Engenheiro Agrônomo, Dr. Prof. Adjunto - Fac. de Agronomia e Medicina Veterinária Universidade de Brasilia. E-mail: jxavier @unb.br

Recebido em agosto de 2002 e aceito em dezembro de 2002 
uma das atividades do agronegócio de maior importância nos próximos anos, podendo contribuir desta forma para o desenvolvimento econômico e social do País (Pinazza \& Alimandro, 1999, p. 227-228).

Infelizmente, com deficiências na estrutura e organização, o agronegócio frutícola brasileiro, a despeito de seu potencial, segue com dificuldades. Entretanto, atualmente, depois das grandes transformações estruturais ocorridas na agricultura brasileira e da emergência do conceito de agribusiness, é possível entender-se a cadeia produtiva frutícola como um todo, sem a segmentação antes presente, visualizar os pontos de estrangulamento e atacar seus principais problemas.

Dentre as diversas regiões brasileiras produtoras de frutas, o Estado de Goiás não tem tradição e nem tampouco produção expressiva, embora possua as condições necessárias para tal e já tenha envidado esforços no sentido de estabelecer o desenvolvimento de pólos de fruticultura em algumas regiões. O Programa de Fruticultura do Oeste Goiano, objeto do presente estudo, iniciou-se em 1993, envolvendo 106 (cento e seis) produtores de 09 (nove) municípios, localizados na região Oeste de Goiás, sendo articulado por instituições estaduais e municipais. Apesar dos esforços, o Programa não se consolidou frustrando, particularmente, os produtores rurais envolvidos.

Importa perguntar: quais as causas do insucesso de programas dessa natureza? Procurando respostas, neste trabalho seguiu-se uma linha de raciocínio objetivando a construção e sustentação de uma hipótese acerca da importância da coordenação da cadeia produtiva, sob a ótica da visão sistêmica do agronegócio - na produção de frutas - como elemento dinamizador da competitividade e indutor da consolidação das ações implementadas para a criação de pólos de fruticultura, a partir da experiência do Programa de Fruticultura do Oeste Goiano.

Este trabalho tem por objetivo estudar, sob a ótica da visão sistêmica do agronegócio, as principais causas relacionadas às dificuldades na implantação e viabilização do Programa de Fruticultura do Oeste Goiano, defendendo a hipótese de que as iniciativas de apoio ao Programa de Fruticultura do Oeste Goiano, ao orientarem-se prioritariamente para o segmento da produção, sem incorporar a visão sistêmica do agronegócio e a necessidade de modos de coordenação adequados, não foram suficientes para garantir o desenvolvimento sustentável da atividade na região.

\section{Caracterização Do Objeto De Estudo}

\section{Região do Estudo}

Os municípios que fazem parte da região estudada ocupam uma área aproximada de $15.500 \mathrm{Km}^{2}$ a Oeste do Estado de Goiás, no Centro-Oeste brasileiro, entre os paralelos $16^{\circ} 46^{\prime}$ e $16^{\circ} 58^{\prime} 12^{\prime \prime}$ de Latitude Sul e os meridianos $50^{\circ} 46^{\prime}$ e $52^{\circ} 14^{\prime}$ 'a oeste de Greenwich (SEPLAN-GO, 1994).

Em 1991 a região abrigava uma população de 91.806 habitantes, sendo que desses, $69.33 \%$ localizavam-se na área urbana, e $30.97 \%$ na área rural, apresentando densidade demográfica de 5,85 habitantes/Km2 (IBGE,1991).

O Oeste Goiano, em 1995, caracterizava-se por uma economia assentada basicamente na pecuária extensiva de corte e de leite, pequenas agroindústrias e comércio. A agricultura, com algumas exceções era exclusivamente de subsistência, restrita aos produtos básicos - arroz, feijão e milho - apresentando baixos índices de produtividade.

\section{Programa de Fruticultura do Oeste Goiano}

O Programa de Fruticultura do Oeste de Goiás fez parte do Desenvolvimento Sustentado nos Cerrados do Oeste Goiano, sendo uma iniciativa dos Secretários de Agricultura dos municípios da região, os quais buscaram o apoio do Governo Estadual, através da Secretaria de Estado do Planejamento e Desenvolvimento Regional.

O objetivo inicial do Programa foi implantar um pólo regional de fruticultura, abrangendo nove municípios, a saber: Arenópolis, Bom Jardim de Goiás, Diorama, Doverlândia, Fazenda Nova, Iporá, Jaupaci, Moiporá e Piranhas. Esse pólo seria dotado de infra-estrutura necessária à produção, processamento industrial e comercialização, priorizando as frutas tropicais. 
Começou a ser implementado em 1994, quando 106 produtores foram contemplados com recursos (R $\$ 4,3$ milhões) do FCO (Fundo Constitucional do Centro-Oeste) e plantaram uma área de 625 hectares, incluindo doze espécies de culturas frutíferas.

Por meio de fontes secundárias, tais como registros e laudos das empresas de assistência técnica e do agente financeiro (Banco do Brasil S/A), bem como informações obtidas no trabalho de campo, durante as entrevistas, verificou-se que a atividade da fruticultura, ligada ao Programa nos municípios da região, foi praticamente abandonada

O Programa de Fruticultura do Oeste Goiano foi concebido como um conjunto de instrumentos organizados sob a forma de incentivos, os quais estão relacionados no Quadro 01.

\section{Delimitação da Cadeia Produtiva ${ }^{1}$ Frutícola do Oeste Goiano}

Para melhor compreensão do sistema de produção que se estabeleceu na implementação do Programa, faz-se necessário a delimitação da cadeia produtiva frutícola na região, seus principais

Quadro 01 - Incentivos Aportados pelo Programa de Fruticultura "do Oeste Goiano

\begin{tabular}{|c|c|c|c|}
\hline $\begin{array}{c}\text { Natureza do } \\
\text { Incentivo }\end{array}$ & $\begin{array}{c}\text { Organizaçãol } \\
\text { Instituiçãao }\end{array}$ & $\begin{array}{c}\text { Meta } \\
\text { Prevista }\end{array}$ & Segmento Beneficiado \\
\hline Apoio ao Crédito & Seplan/Banco do Brasil/Beg & $\begin{array}{l}\text { Financiar os projetos } \\
\text { com recursos do FCO }\end{array}$ & $\begin{array}{l}\text { Produtores Rurais } \\
\text { e suas Associaçð̋s }\end{array}$ \\
\hline Fomento à Produçāo & Emgopa/Emater & $\begin{array}{l}\text { Produzir e fornecer } \\
\text { mudas certificadas } \\
\text { aos fruticultores }\end{array}$ & $\begin{array}{l}\text { Produtores Rurais } \\
\text { e suas Associações }\end{array}$ \\
\hline Assistência Técnica & Emater & $\begin{array}{l}\text { Elaborar e implantar os } \\
\text { projetos, prestar Astec } \\
\text { integral e gratuita } \\
\text { aos produtores }\end{array}$ & $\begin{array}{l}\text { Produtores Rurais } \\
\text { e suas Associaçðes }\end{array}$ \\
\hline
\end{tabular}

Cadeia Produtiva: seqüência de operaçōes que conduzem à produção de bens. Sua articulação é amplamente influenciada pela fronteira de possibilidades ditadas pela tecnologia e é definida pelas estratégias dos agentes que buscam a maximizaçāo pela seus lucros. As relações entre os agentes são de interdependência ou complementaridade e sāo determinadas por forças hierárquicas. Em diferentes niveis de análise, a cadeia é um sistema mais ou menos capaz de assegurar sua própria transformação (Morvan, 1985).

\begin{tabular}{|c|c|c|c|}
\hline Apoio à Pesquisa & Emgopa/Emater & \begin{tabular}{|l|} 
Instalação de um Campo \\
de Pesquisa Experimenta! \\
de Fruticultura na regiăo
\end{tabular} & \begin{tabular}{|l|} 
Produtores Rurais \\
e suas Associą̧⿸尸es
\end{tabular} \\
\hline Capacitaçāo & \begin{tabular}{|l} 
Emater \\
Sebrae/Emgopa
\end{tabular} & $\begin{array}{l}\text { Realizar cursos, } \\
\text { treinamentos, dias de } \\
\text { campo, excursőes } \\
\text { técnicas,palestras } \\
\text { seminários, preparar } \\
\text { folders, apostilas, etc. }\end{array}$ & \begin{tabular}{|l} 
Produtores Ruratis \\
e suas Associaçðes \\
Agroindústrias/ \\
Processadoras de Frutas
\end{tabular} \\
\hline $\begin{array}{l}\text { Apoio à Implantação } \\
\text { de Agroindústrias }\end{array}$ & $\begin{array}{l}\text { Seplan/Sictur/ } \\
\text { Emater/Banco } \\
\text { do Brasil }\end{array}$ & $\begin{array}{l}\text { Viabilizar recursos para a } \\
\text { criaçio de Distritos Agro- } \\
\text { Industriais na região. }\end{array}$ & $\begin{array}{l}\text { Produtores Rurais e } \\
\text { suas Associaçōes }\end{array}$ \\
\hline Associativismo & $\begin{array}{l}\text { Sec. Municipais de } \\
\text { Agricultura/Sebrae/ } \\
\text { Emater/Banco do Brasil }\end{array}$ & \begin{tabular}{|l|} 
Criar a Central de \\
Fruticultura do Oeste \\
Goiano; promover \\
atividades p/fortalecer a \\
organização e participação \\
dos produtores rurais.
\end{tabular} & $\begin{array}{l}\text { Produtores Rurais e } \\
\text { suas Associaçōes }\end{array}$ \\
\hline $\begin{array}{l}\text { Apoio a } \\
\text { Infra-estrutura Local }\end{array}$ & Prefeituras dos municípios & \begin{tabular}{|l|} 
Criar consórcio \\
intermunicjpal \\
$\mathrm{p}^{\prime}$ atender demandas dos \\
fruticuttores
\end{tabular} & \\
\hline Comercializaçăo & $\begin{array}{l}\text { Prefeituras/Emater/Sebrae/ } \\
\text { Banco do Brasil S/A }\end{array}$ & $\begin{array}{l}\text { Assessoria gerencial e } \\
\text { apoio logistico para o } \\
\text { transporte. }\end{array}$ & $\begin{array}{l}\text { Produtores Rurais e } \\
\text { suas Associaçōes }\end{array}$ \\
\hline
\end{tabular}

Fonte: Elaborado pela autora com base em documentos do Programa de Fruticultura do Oeste Goiano.

segmentos, a forma de organização existente, bem como as organizações e instituições participantes.

O ambiente organizacional era composto por órgãos de extensão rural e pesquisa (EMATER-GO e EMGOPA), associações de produtores, comerciantes de frutas, empresas de planejamento agropecuário, prefeituras municipais e respectivas secretarias de agricultura, banco (Banco do Brasil S/A), etc. As tradições, os costumes, as leis municipais, estaduais e federais vigentes, as normas do crédito rural, entre outros faziam parte do ambiente institucional.

O segmento de insumos era representado por lojas e/ou representantes comerciais de produtos agropecuários, máquinas 
e equipamentos agrícolas situados na região e em Goiânia, capital do Estado.

Os bens de capital foram financiados com recursos do FCO, fundo administrado pelo Banco do Brasil S/A.

O segmento de produção agrícola era formado pelo sistema de produção (os pomares), sendo que não contavam com estrutura de pós-colheita (packing house).

Outro elo da cadeia era representado pelo segmento de distribuição, formado por: 1) atacadistas da CEASA; 2) supermercados; 3) pequenas agroindústrias caseiras; 4) frutarias; 5) feiras, etc. A maior parte da produção era comercializada in natura. Uma pequena parte era destinada a agroindústrias artesanais de polpas e doces de frutas.

No final da cadeia estão os consumidores do mercado interno, já que o Programa não visava o mercado externo.

\section{Referencial Teórico}

\section{“Agribusiness", Enfoque Sistêmico e Coordenação}

O conceito de "agribusiness" trata da agricultura e dos negócios que esta envolve desde o "antes da porteira" até o "pósporteira" (Neves, 1995). Apesar de recente no Brasill ${ }^{2}$, este termo aparece pela primeira vez em 1957 na Universidade de Harvard, quando os Professores John Davis e Ray Goldberg o formalizaram como sendo:

"a soma total das operações de produção e distribuição de suprimentos agrícolas, das operações de produção nas unidades agrícolas, do armazenamento, processamento e distribuição dos produtos agrícolas e ítens produzidos a partir deles."3

${ }^{2}$ Não há tradução adequada para o Português. Araujo, Wedekin e Pinazza são os principais responsáveis pela massificaçāo do termo no Brasil, como livro "Complexo Agroindustrial" O Agribusiness Brasileird", de 1990. Porém, alguns estudiosos utizam o termol. "agronegócio" para traduzi-io.

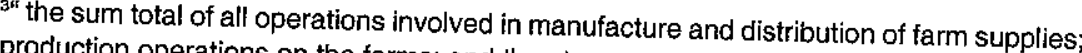
production operations on the farms; and the storage, processing and distribution of farm commodities and items made from them" (Davis, J. \& Goldberg, R.A1957, p. 85).
Para Davis e Goldberg, os problemas relacionados com o setor agroalimentar eram muito mais complexos que a simples atividade rural. Partiu daí a necessidade de estudar esses problemas sob a ótica do agribusiness e não mais com o enfoque estático da agricultura.

A Nova Economia das Instituições, também denominada Economia dos Custos de Transação, da forma como desenvolvida por Williamson $(1979,1989,1991)$, seguindo a teoria iniciada por Coase (1937), permite uma linha de raciocínio adequada para compreender a coordenação como um elemento-chave da competitividade. Ressalta a importância dos aspectos institucionais da produção e critica a teoria econômica clássica, que estuda os modos de coordenação somente via preços.

Williamson (1993) apud Zylbersztajn (1995, p.14-15) denomina de "ficção do custo de transação igual a zero" aos pressupostos neoclássicos e afirma que os arranjos institucionais de governança são uma resposta minimizadora de ambos os custos, os de transação e os de produção.

A metodologia de análise proposta neste estudo toma por referência conceitual principal o enfoque sistêmico de produto (commodity systems approach-CSA), complementado pelo enfoque mais recente de supply chain management (SCM). Essa metodologia reconhece a importância de ações sistêmicas que afetam a competitividade da cadeia produtiva como um todo e dos agentes que a integram. A abordagem sistêmica do CSA está fundamentada em estudos originalmente desenvolvidos nas ciências biológicas e engenharias, que encontraram receptividade em outras disciplinas a partir da década de 40 , principalmente em razão dos trabalhos de um grupo de pesquisadores do Instituto de Tecnologia de Massachussets (MIT) nos EUA (Silva \& Batalha,1999, p.19).

O enfoque sistêmico de produto oferece o arcabouço teórico necessário à compreensão da forma como a cadeia funciona e sugere as variáveis que afetam o desempenho do sistema.

O planejamento e a gestão das políticas públicas voltadas aos agronegócios brasileiros têm sido historicamente concebidos sob um enfoque pontual ou setorial, com ações centradas no segmento agrope- 
cuário. Com a emergência de uma economia agroindustrial voltada à qualidade e à segurança alimentar, a estruturação atual do agronegócio passa a focalizar e orientar-se pela demanda. Analisando essas questões, Leite \& Pessoa (1996) enfatizam que no contexto atual é necessário que os tomadores de decisão tenham uma visão sistêmica do negócio, que vislumbrem o todo, suas partes relevantes e seus inter-relacionamentos.

A competitividade de uma cadeia produtiva é expressa pela sua capacidade de implementar estratégias concorrenciais que the possibilitem uma inserção sustentável no mercado (Ferraz et alii, 1996). Portanto, as intervenções tecnológicas e as melhorias organizacionais, através de uma boa coordenação, são meios imprescindíveis à sua permanência e melhor inserção no mercado.

O processo de coordenação de uma cadeia precisa gerar incentivos e controles para que se reduzam os custos de transação. Neste contexto, a competitividade dinâmica das cadeias agrícolas, no sentido de maior adaptação ao ambiente econômico, depende de uma coordenação eficiente.

No caso do Programa de Fruticultura do Oeste Goiano, pretendemos demonstrar neste estudo que o planejamento e a implementação das ações desenvolvidas tiveram o foco voltado prioritariamente para o segmento da produção, não criando as condições necessárias para a emergência de estruturas de coordenação e governança, capazes de garantir a sustentabilidade e continuidade da atividade produtiva.

\section{Metodologia}

A metodologia utilizada neste trabalho é a de estudo de caso, com pesquisa de campo servindo-se do método de análise rápida Rapid Rural Appraisal (RRA $)^{4}$, proposto por Holtzman et al. (1995) apud Bando (1998), sendo também adotado por Chambers (1992), Dunn (1994), Townsley (1996), entre outros. Esse método consiste no uso

${ }^{4}$ Para este estudo utilizou-se a terminologia Rapid Rural Appraisal (RRA), já que é o método de análise rápida que consideramos mais adequado a estudos ligados ao intensivo de fontes secundárias, observações "in loco", amostras não probabilísticas (intencionais) e entrevistas semi-estruturadas com pessoas-chaves (especialistas, dirigentes de agroindústrias, dirigentes e funcionários de empresas públicas e privadas, produtores rurais, dirigentes de associações de produtores, pesquisadores e técnicos, extensionistas rurais, dentre outros), todos de algum modo envolvidos na formulação e implementação das ações desenvolvidas para a implantação do Programa de Fruticultura do Oeste Goiano.

\section{Procedimento Metodológico do Estudo}

O Programa de Fruticultura do Oeste Goiano foi implementado entre os anos de 1993 e 1995 . O presente estudo, realizado de forma ex post, foi desenvolvido entre os anos de 2001 e 2002.

As entrevistas realizadas foram conduzidas com perguntas definidas e semi-estruturadas, possibilitando ao entrevistado a liberdade de expressar livremente suas opiniões, percepções, crenças, atitudes, etc. A fim de evitar erros de interpretação e/ou de direcionamento de respostas, optou-se por formular perguntas que permitissem respostas abertas, também mais apropriadas para tratar de questões complexas. Utilizando-se o enfoque descrito, este trabalho foi desenvolvido em etapas, apresentadas e explicadas na seqüência.

Na primeira etapa realizou-se um levantamento de dados e informações sobre o Programa, os quais foram obtidos através de visitas à região de estudo, junto às organizações/instituições responsáveis pela implementação do mesmo. Foram identificados os incentivos programados, por quem, em que época e como estes seriam implementados. Com esse material, preparou-se dois tipos de roteiro para entrevistas semi-estruturadas: o primeiro, com 10 (dez) perguntas relativas aos incentivos aportados pelo Programa, aplicado a uma amostra de 45 (quarenta e cinco) produtores rurais (aproximadamente 5 de cada Município), avaliando o grau de realização do que foi proposto, de que forma os incentivos foram implementados, que tipo de ações foram desenvolvidas no decorrer do processo, e uma questão final onde cada entrevistado, diante da relação dos incentivos, opinou 
classificando-os pela ordem de importância para o sucesso de programas de desenvolvimento da fruticultura; outro com 10 (dez) questões, para identificar e analisar a estrutura de coordenação predominante na cadeia, através do relacionamento entre os agentes, um com perguntas para produtores, e outro para os compradores, com pequenas modificações.

\section{Tabela 01 - Matriz para Análise do Relacionamento entre os Agentes}

\begin{tabular}{lc}
\hline \multicolumn{1}{c}{ Pressupostos } & Análise e Observações das Entrevistas \\
\hline Objeto da Transação & Frutas \\
Frequência & Baixa - Média - Alta \\
Incerteza & Baixa - Média - Alta \\
Especificidade do Ativo & Baixa - Média - Alta \\
Oportunismo & Baixa - Média - Alta \\
Racionalidade Limitada & Baixa - Média - Alta \\
Despesas Administrativas & Baixa - Média - Alta \\
Despesas com Tecnologia de Informação & Baixa - Média - Alta \\
Contribuição Institucional & Baixa - Média - Alta \\
Arbitragem & A ser analisada (privada/pública) \\
Estrutura de Governança Esperada & Mercado - Contratos - Internalização \\
Estrutura de Governança Atual & A ser analisada \\
\hline
\end{tabular}

Fonte: Loader (1996) apud Bando (1998).

A semi-estruturação das entrevistas, nesta etapa, baseou-se no roteiro proposto por Loader (1996) apud Bando (1998 p. 36), cuja adaptação está descrita na Tabela 01.

Para analisar o relacionamento entre os agentes, utilizando-se a matriz de Loader (op. cit.), seguiram-se os parâmetros preconizados na Economia dos Custos de Transação (ECT):

i.Se a Especificidade do Ativo for alta, a estrutura de coordenação via mercado será improvável, prevalecendo então as estruturas de completa integração vertical e/ou formas contratuais.
Eloisa Helena Longhi \& Josemar $X$ de Medeiros / IMPORTANACIA DA COORDENAÇAO NAS CADEIAS PRODUTIVAS

ii. Se o Oportunismo está presente, regras no relacionamento entre os agentes devem ser desenhadas (formas contratuais).

iii. Se a Racionalidade Limitada está presente, justificam-se as possibilidades de quebras contratuais, devido às dificuldades de delinear um contrato com todas as considerações ex-ante, aumentando as incertezas.

iv. Se as transações são Frequientes, é provável que a relação entre os agentes apresente algum modo regular de estrutura de governança.

v. Se as Despesas Administrativas forem altas, médias e baixas no estabelecimento das transações, predominarão as formas de maior, intermediária e menor internalização das transações na empresa, respectivamente.

vi. Quanto menores as despesas com obtenção de Informação sobre as condições de oferta e demanda por parte dos agentes, maior é a integração vertical.

vii. Quanto maior a Contribuição Institucional, maiores serão a orientação e o controle sobre os segmentos do sistema. de produção e comercialização.

viii. A efetiva ação dos mecanismos de Arbitragem da transação, contribuem para a coordenação vertical via arranjos contratuais.

ix. Se as transações têm certo grau de Incerteza, há necessidade de estabelecer relacionamentos (T2) formalizados.

\section{Resultados e Discussão}

A partir da identificação e análise dos incentivos aportados pelo Programa (Quadro 01), observa-se que a maior parte desses incentivos estavam com o foco voltado ao segmento de produção. Houve um esforço concentrado e segmentado, privilegiando o 'dentro da porteira' em detrimento dos demais segmentos da cadeia produtiva frutícola, sendo que o aspecto sistêmico de produção não foi incorporado pelos formuladores das políticas públicas responsáveis pelo Programa. 


\section{Avaliação dos Incentivos Propostos No Programa}

Os incentivos foram primeiramente identificados e classificados conforme a natureza de cada um, dentro dos segmentos participantes da cadeia estudada. Essa classificação seguiu a lógica da visão sistêmica de produção, tomando-se como base a formulação do Programa, onde os incentivos foram agrupados em quatro segmentos da cadeia produtiva frutícola:

(i) Incentivos ao Segmento de Produção: Apoio ao Crédito, Fomento à Produção, Assistência Técnica, apoio à Pesquisa e Capacitação.

(ii) Incentivos ao Segmento de Processamento/Agroindústria: Apoio à Implantação de Agroindústrias.

\section{Quadro 02 - Avaliação e Análise dos Incentivos}

\begin{tabular}{|l|l|l|}
\hline \multicolumn{1}{|c|}{ Incentivos } & \multicolumn{1}{|c|}{$\begin{array}{c}\text { Avaliação sob a } \\
\text { Ótica dos Produtores }\end{array}$} & $\begin{array}{l}\text { Análise sob a Visão } \\
\text { Sistêmica do Agronegócio }\end{array}$ \\
\hline $\begin{array}{l}\text { Apoio ao Crédito } \\
\text { (Análise de projetos, } \\
\text { liberação dos recursos e } \\
\text { condiçōes de crédito) }\end{array}$ & $\begin{array}{l}\text { Considerado "bom" por 50\% } \\
\text { dos produtores, "razoável" } \\
\text { por 42\% e "insatisfatório" } \\
\text { por 8\% deles. }\end{array}$ & $\begin{array}{l}\text { A partir dos resultados, } \\
\text { verifica-se que a política } \\
\text { de crédito revela um ambiente } \\
\text { institucional (normas de crédito: } \\
\text { taxa de juros, prazo e forma } \\
\text { de pagamento, garantias) com } \\
\text { razó́vel nível de adequação. }\end{array}$ \\
$\begin{array}{l}\text { Fomento à Produçāo } \\
\text { fornecimento de mudas, } \\
\text { máquinas e implementos } \\
\text { agrícolas de uso coletivo) }\end{array}$ & $\begin{array}{l}\text { Todos os produtores } \\
\text { entrevistados classificaram a a } \\
\text { implementação do incentivo } \\
\text { como "insatisfatória". }\end{array}$ & $\begin{array}{l}\text { As dificuldade na } \\
\text { implementação do incentivo } \\
\text { denota um ambiente } \\
\text { organizacional inadequado. } \\
\text { O modo de domínio via } \\
\text { mercado foi incapaz de estimular } \\
\text { mecanismos supridores } \\
\text { dos principais insumos. }\end{array}$ \\
\hline
\end{tabular}

\begin{tabular}{|c|c|c|}
\hline $\begin{array}{l}\text { Assistência Técnica } \\
\text { (elaboração dos projetos } \\
\text { técnicos e assistência } \\
\text { técnica integral aos produtores) }\end{array}$ & $\begin{array}{l}\text { Quanto ao deseffipenho da Astec, } \\
\text { os produtores dividiratn-8e: } \\
42,2 \% \text { considerou "regular", } \\
42,2 \% \text { "insatisfatório" e } 15,6 \% \\
\text { disseram ter sido "bom". }\end{array}$ & $\begin{array}{l}\text { O modelo de assistência técnica } \\
\text { mostrou-se inadequado e } \\
\text { insuficiente para fazer a gestão } \\
\text { tecnológica da cadeia. Como } \\
\text { um serviço prestado pelo Estado, } \\
\text { não obedeceu a um sistema de } \\
\text { coordenação onde são } \\
\text { relevantes tanta a dimensão } \\
\text { tecnológica quanto a técnica. }\end{array}$ \\
\hline $\begin{array}{l}\text { Apoio à Pesquisa (instalação de } \\
\text { um Campo Experimental } \\
\text { p/ produção de mudas e } \\
\text { desenvolver pesquisas com } \\
\text { espécies de frutas tropicais) }\end{array}$ & $\begin{array}{l}\text { O incentivo à pesquisa foi } \\
\text { classificado como } \\
\text { "insatisfatório" por } 100 \% \\
\text { dos entrevistados. }\end{array}$ & $\begin{array}{l}\text { Ficou evidenciada a total } \\
\text { inadequação do ambiente } \\
\text { organizacional para a pesquisa. } \\
\text { Assim como a assistência } \\
\text { técnica, a pesquisa está } \\
\text { embutida no processo de gestão } \\
\text { tecnológica na coordenação das } \\
\text { cadeias produtivas frutícolas. }\end{array}$ \\
\hline $\begin{array}{l}\text { Capacitação } \\
\text { (capacitação técnica e gerencial, } \\
\text { treinamentos em comercialização } \\
\text { e informaçōes de mercado, dias } \\
\text { de campo, seminários e } \\
\text { excursóes técnicas) }\end{array}$ & $\begin{array}{l}\text { Fol avaliado como "regular" por } \\
42,3 \% \text { dos produtores e como } \\
\text { "insatisfatório" pelos } 57,7 \% \\
\text { restantes. }\end{array}$ & $\begin{array}{l}\text { Pelo resultado, verifica-se } \\
\text { que o modo de transferência } \\
\text { de tecnologia e ensino não } \\
\text { foi adequado aos processo. } \\
\text { A capacitação, juntamente } \\
\text { com a pesquisa e extensão, } \\
\text { constituem o tripé da gestão } \\
\text { tecnológica, atuando como } \\
\text { suporte à produção no âmbito } \\
\text { do processo de coordenação } \\
\text { da fruticultura. }\end{array}$ \\
\hline $\begin{array}{l}\text { Implantação de Agroindústrias } \\
\text { (atrair o interesse de empresários } \\
\text { para a instalaçāo de } \\
\text { agroindústrias processadoras de } \\
\text { frutas na regiāo) }\end{array}$ & $\begin{array}{l}\text { O incentivo foi considerado } \\
\text { "insatisfatório" pelos } 45 \\
\text { produtores entrevistados. }\end{array}$ & $\begin{array}{l}\text { A política de estímulo a } \\
\text { agroindústrias denota um } \\
\text { ambiente institucional pouco } \\
\text { adequado para atrair } \\
\text { investimentos na região. } \\
\text { Revela a dificuldade de } \\
\text { visualizar o aspecto sistêmico } \\
\text { da produção por parte dos } \\
\text { atores participantes da cadeia. }\end{array}$ \\
\hline
\end{tabular}




\begin{tabular}{|c|c|c|}
\hline $\begin{array}{l}\text { Associativismo } \\
\text { (incentivar o associativismo } \\
\text { criando uma central de } \\
\text { associaçōes de fruticultores } \\
\text { na regiāo) }\end{array}$ & $\begin{array}{l}\text { Dos produtores entrevistados, } \\
91 \% \text { avaliou o incentivo como } \\
\text { "insatisfatório", sendo que os } \\
\text { demais classificaram-no } \\
\text { como regular. }\end{array}$ & $\begin{array}{l}\text { A estruturação inadequada } \\
\text { dos ambientes institucional/ } \\
\text { organizacional não foram } \\
\text { suficientes p/consolidar o } \\
\text { associativismo entre } \\
\text { os produtores. }\end{array}$ \\
\hline $\begin{array}{l}\text { Apoio à Infra-estrutura Local } \\
\text { (consórcio intermunicipal de } \\
\text { máquinas e implementos, } \\
\text { infra-estrutura p/ irrigação, } \\
\text { energia, transporte, etc. }\end{array}$ & $\begin{array}{l}\text { Do total, } 40 \% \text { dos produtores } \\
\text { consideraram "insatisfatório", } \\
40 \% \text { "regular", } 11 \% \text { "bom e } 9 \% \\
\text { "excelente". }\end{array}$ & $\begin{array}{l}\text { Revela ambientes institucional } \\
\text { e organizacional com certa } \\
\text { adequação. A falta de um agente } \\
\text { coordenador, juntamente com a } \\
\text { dificuldade de trabalho } \\
\text { cooperativo, teve impacto } \\
\text { negativo na implementação } \\
\text { do incentivo. }\end{array}$ \\
\hline $\begin{array}{l}\text { Apoio à comercialização } \\
\text { (criar um central de associaçōes } \\
\text { dos fruticultores para gerenciar } \\
\text { a comercialização, dando } \\
\text { suporte à pós-colheita e } \\
\text { transporte da produção) }\end{array}$ & $\begin{array}{l}\text { Todos os produtores } \\
\text { avaliaram como "insatisfatớrio" } \\
\text { o que estava previsto para } \\
\text { appoiar a comercialização }\end{array}$ & $\begin{array}{l}\text { Para fazer a coordenação da } \\
\text { comercialização adotou-se a } \\
\text { estratégia de organização dos } \\
\text { produtores. Essa revelou-se } \\
\text { inadequada, porque o } \\
\text { associativismo não se } \\
\text { estabeleceu. Por outro lado, o } \\
\text { modo de domínio via mercado } \\
\text { também mostrou-se inadequado } \\
\text { para a sustentabilidade do } \\
\text { processo de comercialização }\end{array}$ \\
\hline
\end{tabular}

Fonte: Pesquisa de Campo.

(iii) Incentivos aos Ambientes Institucional/Organizacional: Associativismo e Apoio à Infraestrutura.

(iv) Incentivo ao Segmento de Comercialização/Distribuição: Apoio à Comercialização da Produção

Cada um dos incentivos foi avaliado, conforme a percepção de cada produtor entrevistado, quanto ao seu impacto efetivo na implementação do seu projeto, em particular, e do Programa, em geral. Para isso utilizou-se uma escala nominal (ver Figura 01).

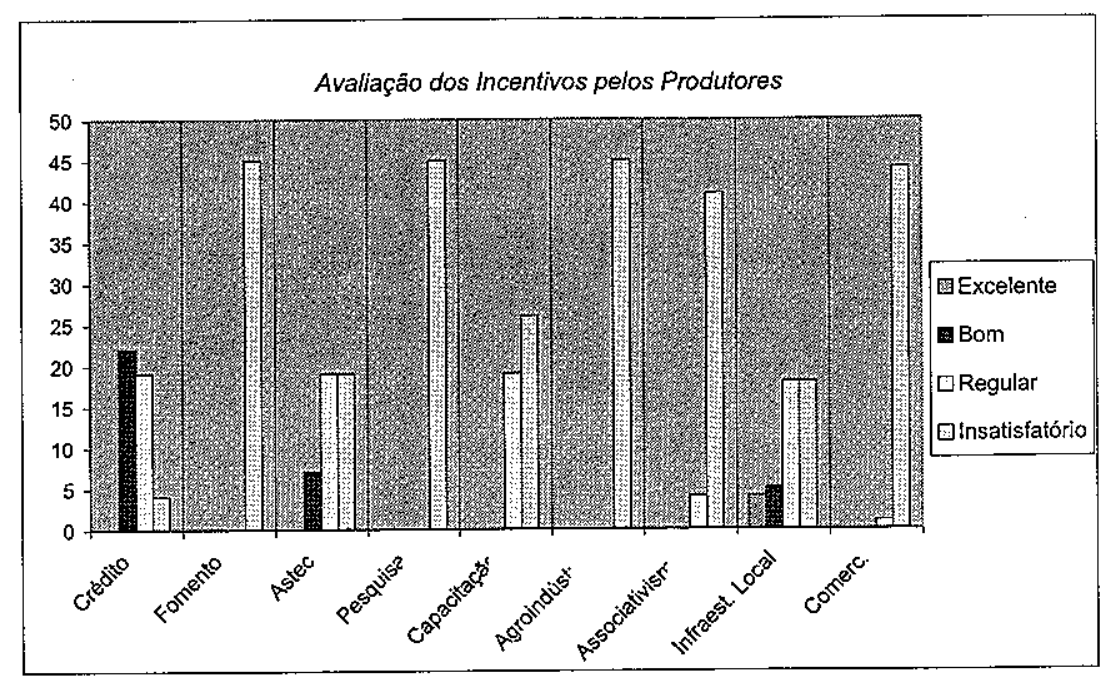

Figura 01 - Resultado da Avaliação dos Principais Incentivos pelos Produtores

\section{Avaliação Da Importância Relativa Dos Incentivos}

Observando-se o resultado da classificação dos incentivos pela ordem de importância (Figura 02), podemos constatar que os produtores, ao eleger como primeiro e segundo colocados a comercialização e a assistência técnica, respectivamente, inconscientemente apontam para a necessidade de uma estrutura de "coordenação" na cadeia produtiva frutícola, que incorpore de forma clara e com eficiência, as dimensões econômica e técnica.

Não é por acaso que os resultadós evidenciam a comercialização, dentre todos os incentivos relacionados, como o segmento mais importante para que o desenvolvimento de pólos de produção de frutas se consolidem como uma atividade atrativa e rentável. 


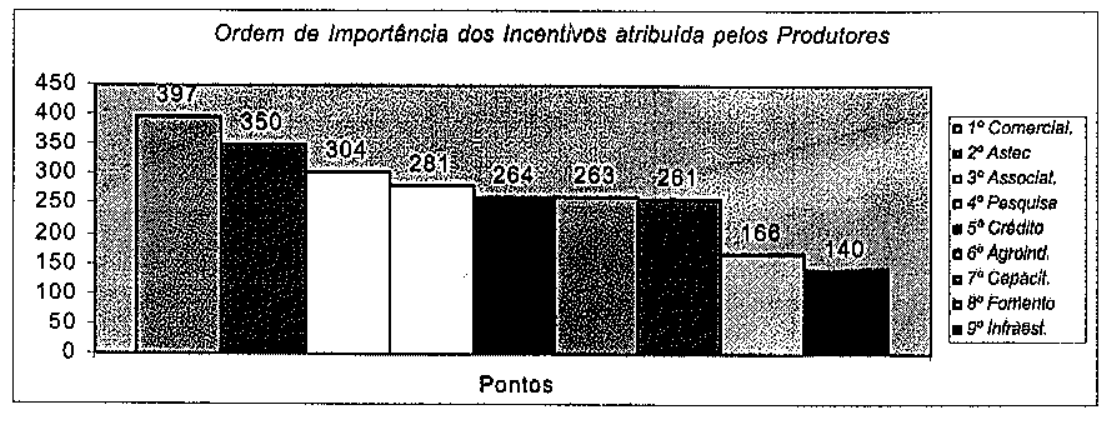

Figura 02 - Ordem de Importância dos Incentivos Atribuída pelos Produtores

No penúltimo e último lugares, estão o fomento à produção e a infra-estrutura local, considerados de menor importância. Como são incentivos que geralmente ficam a cargo dos poderes públicos (municipal, estadual, federal), chamam a atenção para a necessidade de uma reflexão sobre o papel do estado atuando menos como agente "provedor" e mais como agente "regulador" e "conformador" dos ambientes institucional e organizacional, conforme vem se observando no agronegócio de modo geral.

\section{Análise da Relação da Transação entre Fruticultor e Comprador de Frutas}

Para analisar a estrutura de coordenação predominante na relação entre fruticultores e compradores de frutas, adaptou-se o roteiro de Loader, 1996 (op. cit.), com os resultados demonstrados nas Tabelas 02 e 03.

$\mathrm{O}$ atacadista, pela própria natureza do trabalho, opera numa lógica muito diferente das agroindústrias. Ele vive de administrar expectativas, descobrir oportunidades. Para o administrador de expectativas sempre é melhor a coordenação via preço de mercado, pois tem acesso à informação e fornecedores externos. Esta situação aponta para a fragilidade desse tipo de modelo, que foi adotado pelo Programa de Fruticultura do Oeste Goiano.
Tabela 02 - Relação da Transação T2 entre os Agentes na Visão dos Produtores

\begin{tabular}{|c|c|}
\hline Pressupostos & Resultado e Análise das Entrevistas \\
\hline Objeto da Transação & Frutas in natura. \\
\hline Frequência & $\begin{array}{l}\text { Alta - para atender a demanda do mercado } \\
\text { de frutas frescas, que é muito dinâmico. }\end{array}$ \\
\hline Incerteza & $\begin{array}{l}\text { Alta - riscos de super-oferta e quedas } \\
\text { abruptas de preços. }\end{array}$ \\
\hline Especificidade do Ativo & $\begin{array}{l}\text { Alta - alta perecibilidade do produto e } \\
\text { poucas opções de colocação no mercado. }\end{array}$ \\
\hline Oportunismo & $\begin{array}{l}\text { Alto - ausência de vendas através de } \\
\text { contratos. }\end{array}$ \\
\hline Racionalidade Limitada & $\begin{array}{l}\text { Média/Alta - dificuldade no cumprimento } \\
\text { de acordos prévios. }\end{array}$ \\
\hline Despesas Administrativas & $\begin{array}{l}\text { Baixa - apenas de cadastro do produtor, às } \\
\text { vezes nem isso. }\end{array}$ \\
\hline Despesas com Informação & $\begin{array}{l}\text { Alta - pesquisa de mercado a } \\
\text { cada transação. }\end{array}$ \\
\hline $\begin{array}{l}\text { Contribuição Institucional/ } \\
\text { Organizacional }\end{array}$ & $\begin{array}{l}\text { Baixa - ambientes institucional e } \\
\text { organizacional desestruturados. }\end{array}$ \\
\hline Arbitragem & Baixa - ausência de regras estabelecidas. \\
\hline Estrutura de Governança Esperada & Via contratual \\
\hline Estrutura de Governança Praticada & Via preço de mercado \\
\hline
\end{tabular}

Fonte: Pesquisa de Campo. 
Tabela 03 - Relação da Transação T2 entre os Agentes na Visão dos Compradores

\begin{tabular}{|c|c|}
\hline Pressupostos & Resultado e Análise das Entrevistas \\
\hline Objeto da Transação & Frutas in natura \\
\hline Frequiência & $\begin{array}{l}\text { Alta - para atender a demanda do mercado } \\
\text { de frutas frescas, que é muito dinâmico. }\end{array}$ \\
\hline Incerteza & $\begin{array}{l}\text { Baixa - bastante oferta de frutas, podendo-se } \\
\text { recorrer às importações em casos de } \\
\text { suboferta. }\end{array}$ \\
\hline Especificidade do Ativo & $\begin{array}{l}\text { Alta - produtos perecíveis envolvendo uma } \\
\text { complexa cadeia produtiva. }\end{array}$ \\
\hline Oportunismo & $\begin{array}{l}\text { Médio/Baixo - o produtor não tem muitas } \\
\text { opções sendo melhor cumprir os acordos. }\end{array}$ \\
\hline Racionalidade Limitada & $\begin{array}{l}\text { Média-dificuldade no cumprimento } \\
\text { de acordos prévios. }\end{array}$ \\
\hline Despesas Administrativas & $\begin{array}{l}\text { Baixa - apenas de cadastro } \\
\text { do produtor, às vezes nem isso. }\end{array}$ \\
\hline Despesas com Informação & $\begin{array}{l}\text { Média - fornecedores garantidos, sem muita } \\
\text { necessidade de monitoramento constante. }\end{array}$ \\
\hline $\begin{array}{l}\text { Contribuição Institucional/ } \\
\text { Organizacional }\end{array}$ & $\begin{array}{l}\text { Baixa - ambientes institucional e } \\
\text { organizacional desestruturados. }\end{array}$ \\
\hline Arbitragem & $\begin{array}{l}\text { Baixa - ausência de regras estabelecidas } \\
\text { para ambas as partes. }\end{array}$ \\
\hline Estrutura de Governança Esperada & Mista (via mercado e/ou contratual) \\
\hline Estrutura de Governança Praticada & Via preço de mercado \\
\hline
\end{tabular}

Fonte: Pesquisa de Campo.
Analisando-se a visão que os produtores têm do relacionamento entre os agentes (Tabela 02), percebe-se que a "frequiência", a "especificidade dos ativos" e a "incerteza" são altas, o que remete à necessidade de uma estrutura de coordenação contratual, principalmente para os produtores.

O nível de "incerteza" da transação a ser efetuada localmente foi considerada alta. Porém os compradores buscam produtos em outras praças ou mesmo importam, para reduzir esta incerteza no suprimento. A diferença básica, comparando-se a visão dos produtores com a dos compradores (Tabela 03), é que na visão dos últimos a incerteza é baixa. Isto se explica porque este agente (o comprador) tem outras alternativas arranjadas para situações de riscos de suprimento, tal como a aquisição em outras regiões, não necessitando recorrer a arranjos contratuais com fornecedores, já que o risco não é alto.

$\mathrm{O}$ "oportunismo" entre as partes é alto, visto que se trata de um mercado oligopsônico, onde existem muitos vendedores e poucos compradores, o que deixa os produtores com elevada dependência em relação aos compradores.

Houve pequena variação para a "racionalidade limitada": considerada alta para os produtores e média pelos compradores.

A "despesa administrativa" é baixa para ambos os agentes, já que não são elaborados contratos, apenas cadastros em alguns casos.

Para os produtores a "despesa com informação" é alta, pois a cada venda há a necessidade de obter informações com os possíveis compradores, a fim de acertar os detalhes da transação. Para os compradores esta despesa é média, já que os produtores não tem muitas opções de venda do produto, quase sempre acaba recorrendo aos mesmos compradores.

A contribuição institucional/organizacional é baixa na visão de ambas as partes.

Considerada baixa, a "arbitragem" não é possível, pois não existem regras estabelecidas.

\section{Conclusões e Sugestões}

O principal objetivo desta pesquisa foi estudar as causas 
relacionadas às dificuldades na implementação e viabilização do Programa de Fruticultura do Oeste Goiano, analisando-se a formulação e implantação dos projetos, bem como a coordenação da cadeia produtiva frutícola, sob o enfoque sistêmico do agronegócio, apoiandose no referencial teórico de agribusiness proposto por Davis e Goldberg (op. cit.) e seus sucessores, bem como pela Nova Economia Institucional.

A partir desses conceitos aplicados a um caso real, a análise possibilitou algumas conclusões.

A análise das entrevistas com os produtores, juntamente com as informações sobre os incentivos propostos e sobre como foi conduzida a implementação do Programa, revela que as políticas públicas não incorporaram o aspecto sistêmico ao formularem o Programa. Os incentivos previstos orientaram-se principalmente para o segmento de produção, em detrimento dos demais segmentos da cadeia.

Pode-se concluir que, seguramente, a pós-colheita e comercialização foram os principais problemas apontados pelos produtores participantes do Programa. Sabe-se que os problemas de pós-colheita enfrentados pelos pequenos e médios produtores representam o maior desafio que o Estado deve enfrentar no desenho institucional e organizacional de cadeias de produção, preparo e comercialização de frutas. Constatou-se, também, que na visão dos atores analisados, uma mudança em relação à expectativa sobre o papel do Estado na implementação de tais programas. Nessa perspectiva, ao Estado corresponderiam as tarefas de definição do marco legal e o cumprimento das regulamentações existentes, determinação de mecanismos e instrumentos que visem apoiar a competitividade e produtividade, mobilização e animação dos atores para o cumprimento de funções econômicas ausentes na região.

Pelas entrevistas com os produtores e demais integrantes da cadeia na época do Programa, também pode-se concluir que os produtores não tinham volume de produção suficiente para formar um negócio, apenas produziam matéria-prima desconhecendo o enfoque de processos produtivos diferenciados, nem tampouco as preferências dos consumidores. Comercializavam apenas onde produziam, sem agregar valor, nem mesmo do frete. Pensavam no mercado regional e interno (limitado e pouco exigente) e não em exportação. Enfim, havia total separação entre a atividade produtiva e o conhecimento do mundo dos negócios, principalmente sobre o significado e alcance de uma cadeia produtiva integrada.

O resultado da avaliação dos incentivos confirmam, então, a hipótese de que os mesmos foram focados no segmento de produção, sendo que mesmo estes não foram implementados de forma satisfatória, na ótica dos produtores entrevistados.

Quanto à estrutura de coordenação, a análise da matriz de Loader, no que se refere à transação T2 (produtores/compradores), aplicada aos produtores rurais, evidencia a dificuldade de coordenação da cadeia produtiva frutícola, em sua dimensão técnica e econômica, o que sugere a necessidade de formas mais avançadas de governança.

Para os compradores, a análise da relação da transação T2, aponta para a necessidade de coordenação via mercado/contratual. Isso se justifica pelas características desse mercado (poucos compradores), relativamente oligopsônico, e também, pela possibilidade de suprimento de frutas de outras regiões.

\section{Referências Bibliográficas}

BANDO, Paulo Massanore. Coordenação vertical no complexo agroindustrial brasileiro: uma proposta para a Zona da Mata mineira. Dissertação (Mestrado em Agronomia) - Universidade Federal de Viçosa, 1998, $178 \mathrm{p}$.

CHAMBERS, R. Rural: Rapid, relaxed and participatory. Discussion paper 331. Brighton: University of Sussex, Institute of Development Studies . 1992.

COASE, R. H. (1937). The Nature of the Firm. Economic, 4: 386485./1972. Industrial Organization: a proposal for research, in "The firm, the Market and the Law", The University of Chicago Press: 1988, v. V, p. 57-74.

DAVIS, John H. \& Goldberg, Ray A. A Concept of Agribusiness. Division of Research. Graduate School of Business Administration. Harvard University, Boston, 1957. 136 p. 
DUNN, TONY. "Rapid Rural Appraisal: A description of the methodology and its application in teaching and research at Charles Sturt University". Rural Society, Wagga Wagga, Austrália v. 4. n.3/4, dez.1994. Disponível em: <http://www.csu.edu.au/research/crsr/ ruralsoc/v43p30.htm $>$, Acesso em 04 out. 2001.

FERRAZ, J. C.; KUPFER, D. \& HAGUENAUER, L. Made in Brazil: desafios competitivos para a indústria. Rio de Janeiro: Campus, $1996.286 \mathrm{p}$.

INSTITUTO BRASILEIRO DE GEOGRAFIA E ESTATÍSTICA IBGE. Censo Demográfico de 1991. Rio de Janeiro, 1991.

JANK, M. S. et alii. Agribusiness - marketing e estratégias. In: Noções de Economiae Administração Agroindustrial: ESALQ/USP, 1998. MORVAN, Y. Filière de Production. In: Fondaments d'économie industrielle. Economica. 1985. Pp. 199-231.

NEVES, Marcos Fava. Sistema Agroindustrial Citrícola: um exemplo de quase-integração no agribusiness brasileiro. Dissertação (Mestrado) - Faculdade de Economia, Administração e Contabilidade, Universidade de São Paulo, 1995. 119p.

LEITE, Lucas A. de S. \& Paula Pessoa, Pedro F. A. de. Estudo de cadeia produtiva como subsídio à pesquisa e desenvolvimento do " agronegócio. Fortaleza: EMBRAPA - CNPAT, 1996.

PINAZZA, Luis Antonio \& Alimandro, Regis. (orgs.). Agropolos de desenvolvimento: emergência da cadeia da hortifruticultura irrigada. In: Reestruturação do Agribusiness Brasileiro: agronegócios no terceiro milênio. Rio de Janeiro: Associação Brasileira de Agribusiness, 1999. 266p. PROGRAMA de Desenvolvimento da Agricultura Sustentada nos Cerrados do Oeste Goiano: projeto de fruticultura. Plano de Ação. SEPLAN-GO. Goiânia: 1993. 41p.

SILVA, Carlos Arthur Barbosa da. \& Batalha, Mário Otávio. Competitividade em sistemas agroindustriais: metodologia e estudo de caso. In: II Workshop Brasileiro de Gestão de Sistemas Agroalimentares. Ribeirão Preto: PENSA/FEA/USP, 1999. P 9-20.

TOWNSLEY, Philip. Rapid rural appraisal, participatory rural appraisal and aquaculture. FAO fischeries Technical Paper. N. 358. Rome, FAO. 1996.109 p.
WILLIAMSON, Oliver E. "Transaction Costs Economics: the governance of contractual relations. "The Journal of Law and Economics, v. XXII, pages 223-261, October, 1979.

. Las instituciones económicas del capitalismo. Mexico, D.C.: Fondo de Cultura Económica/Economía Contemporánea, 1989. $434 \mathrm{p}$.

Comparative Economic Organization: The analysis of discrete structural alternatives. Administrative Science Quartely, n.36, (June), 1991. p. 269-296.

ZYLBERSZTAJN, Decio. Estruturas de governança e coordenação do "agribusiness": uma aplicação da Nova Economia das Iinstituições. Tese (Livre Docente em Administração) - Faculdade de Economia, Administração e Contabilidade, Universidade de São Paulo, 1995. $238 \mathrm{p}$ 